\title{
HUBUNGAN ANTARA SIKAP DAN PENGHARGAAN TERHADAP KEPATUHAN PEKERJA DALAM PENGISIAN (HAZARD OBSERVATION CARD) DI SALAH SATU PERUSAHAAN PENYIMPANAN BAHAN KIMIA DI KALIMANTAN TIMUR
}

\author{
Ria Purnama Sari
}

\author{
Departemen Keselamatan dan Kesehatan Kerja, Fakultas Kesehatan \\ Masyarakat Universitas Mulawarman, Samarinda Kalimantan Timur \\ Email : riapurnamasari17584@gmail.com
}

\begin{abstract}
Work accidents could occur due to unsafe working conditions and unsafe work behavior. Reporting dangerous events and accidents is a method and procedure that can be done to prevent dangerous events or accidents that recur. Bird's theory states that recurring nearmiss is mostly caused by unsafe behavior that can increase the risk of work accidents. Identification of unsafe behavior can be done with the Behavior Base Safety (BBS) approach, namely through the filling of hazard observation cards. This type of research used quantitative methods with cross sectional design. The number of samples studied was 76 workers with total sampling from workforce population. The study was conducted in July - August 2019. Data analysis in this study used the Spearman Rank test with a value of $(\alpha=0,05)$.

The results showed there were a relationship between attitude variables (Pvalue $=0,013)$ and awardin (Pvalue $=0,016$. It is suggested to improve system of reward in order to increase worker motivation, make safety instructions regarding the obligation to fill a hazard reporting card, discussion forums or meetings related to the STOP Card program, design a interesting safety media communications focused on observing safe and unsafe condition in the work place.
\end{abstract}

Keywords : Hazard Observation Card, Behavior Based Safety

\begin{abstract}
ABSTRAK
Kecelakaan kerja dapat terjadi akibat adanya kondisi kerja dan perilaku kerja yang tidak aman. Pelaporan kejadian berbahaya dan kecelakaan merupakan suatu metode dan prosedur yang dapat dilakukan untuk mencegah kejadian berbahaya maupun kecelakaan terulang kembali. Teori Bird menyebutkan nearmiss yang terus berulang kebanyakan disebabkan unsafe behavior yang dapat meningkatkan resiko kecelakaan kerja. Identifikasi perilaku tidak aman dapat dilakukan dengan pendekatan Behavior Base Safety (BBS) yaitu melalui pengisian kartu observasi bahaya.Jenis penelitian menggunakan metode kuantitatif dengan desain cross sectional. Jumlah sampel yang diteliti adalah seluruh anggota populasi tenaga kerja berjumlah 76 orang sehingga penelitian ini menggunakan total sampling. Penelitian dilakukan pada bulan Juli - Agustus 2019. Analisis data dalam penelitian ini menggunakan uji Rank Spearman dengan nilai $\alpha=0,05$.

Hasil penelitian menunjukan terdapat hubungan antara variabel sikap $(P v a l u e=0,013)$ dan pemberian penghargaan $(P v a l u e=0,016)$. Saran bagi perusahaan perlunya meningkatkan sitem reward untuk meningkatkan motivasi pekerja, membuat safety instruction mengenai kewajiban pengisian kartu pelaporan bahaya, melakukan diskusi dalam forum atau meeting terkait program STOP Card, mendesain media komunikasi K3 terkait langkah-langkah atau prosedur pengamatan kondisi aman dan perilaku tidak aman di lingkungan kerja.
\end{abstract}

Kata Kunci : Kartu Observasi Bahaya, Keselamatan Berbasis Perilaku 


\section{PENDAHULUAN}

Pelaporan kejadian berbahaya dan kecelakaan merupakan suatu metode dan prosedur yang dapat dilakukan untuk mencegah terjadinya kejadian berbahaya serta kecelakaan yang terulang kembali.

International Labour Oganization (ILO) tahun 2018, mencatat lebih dari 1,8 juta kematian akibat kerja terjadi setiap tahunnya di kawasan Asia dan Pasifik. Dua pertiga kematian akibat kerja di dunia terjadi di Asia ${ }^{[5]}$. Kasus kecelakaan kerja tahun 2017 sampai tahun 2018 meningkat $40 \%$ yaitu sebanyak 173.105 kasus dengan klaim Jaminan Kecelakaan Kerja (JKK) sebesar Rp 1,2 triliun untuk 130 ribu kasus kecelakaan kerja. Kejadian kasus kecelakaan kerja yang ditangani, sebagian besar masih didominasi pada lingkungan kerja sektor pabrik yang memiliki resiko besar (BPJS (BPJS Ketenagakerjaan Indonesia, 2019).

Bird menyatakan bahwa near miss yang terus berulang dan kebanyakan disebabkan oleh unsafe behavior dapat meningkatkan resiko dan kecelakaan kerja yang lebih serius. Sebanyak $88 \%$ penyebab kecelakaan kerja adalah unsafe behavior, $10 \%$ disebabkan oleh unsafe condition dan $2 \%$ tidak diketahui penyebabnya (NSC, 2013).

Perilaku manusia merupakan unsur yang memegang peranan penting dalam mengakibatkan kecelakaan kerja. Mengurangi terjadinya kecelakaan kerja dan meningkatkan performance dapat dicapai dengan usaha memfokuskan pada pengurangan perilaku tidak aman (unsafe behavior) salah satunya dengan melakukan pendekatan Behavior Based Safety (BBS) yaitu dengan penerapan Safety Training Observation Program (STOP Card) atau yang dikenal dengan pengisian kartu observasi bahaya. Pelaporan bahaya oleh pekerja merupakan sarana penting untuk mengidentifikasi potensi bahaya dan mencatat ketidak sesuaian sebelum terjadi kecelakaan (Suryatno, 2015).

PT. X merupakan perusahaan nasional yang berlisensi kontraktor, pemasok dan jasa penyewaan. PT. $X$ menyewakan fasilitas penyimpanan untuk bahan kimia dan gas oil. Upaya pencegahan dan pengendalian terhadap risiko kecelakan yang telah dilakukan oleh PT. X yaitu dengan menerapkan Safety Training Observation Program (Program STOP) sebagai kartu observasi bahaya dan pelaporan bahaya dalam menciptakan kondisi lingkungan kerja yang aman. Hasil laporan dari Departemen Health, Safety Environment (HSE) di PT. X mengenai pengisian STOP card yang terkumpul pada priode 20172018 adalah 90 STOP card. Observasi yang dilakukan, dimana masih terdapat kejadian near miss dan masih ditemukannya pekerja yang melakukan perilaku tidak aman pada sekitar area kerja yang memiliki resiko berbahaya.

Dampak yang timbul jika pelaporan bahaya tidak terlaksana dengan baik adalah tidak teridentifikasinya kondisi-kondisi tidak aman maupun perilaku tidak aman di lingkungan kerja yang berpotensi menimbulkan kecelakaan ataupun kejadian yang lebih besar (Winnaputri, Maher Denny and Ekawati, 2017). 


\section{METODE PENELITIAN}

Penelitian ini menggunakan metode kuantitatif dengan desain cross sectional. Populasi penelitian yaitu seluruh tenaga kerja yang berstatus karyawan tetap di luar manajer perusahaan dan koordinator unit atau mandor pada PT. X pada tahun 2019 yang berjumlah 76 orang.

\section{HASIL DAN PEMBAHASAN \\ Hasil \\ Gambaran Karakteristik Responden pada Pekerja}

Tabel 3.1 Distribusi Pekerja Berdasarkan Karakteristik Responden

\begin{tabular}{llcc}
\hline $\begin{array}{l}\text { Variab } \\
\text { el }\end{array}$ & $\begin{array}{l}\text { Karakteristik } \\
\text { Responden }\end{array}$ & $\begin{array}{c}\text { Frekue } \\
\text { nsi } \\
(\mathbf{n = 7 6 )}\end{array}$ & $\begin{array}{c}\text { Persent } \\
\text { ase (\%) }\end{array}$ \\
\hline & $25-29$ tahun & 6 & 7,9 \\
& $30-34$ tahun & 7 & 9,2 \\
Umur & 35-39 tahun & 11 & 14,5 \\
& $45-44$ tahun & 12 & 15,8 \\
& $50-54$ tahun & 18 & 23,7 \\
& $55-59$ tahun & 16 & 21,1 \\
Jenis & L0+ tahun & 1 & 6,6 \\
Kelami & Perempuan & 11 & 1,3 \\
$\mathrm{n}$ & SD & 10 & 13,5 \\
Pendid & SMP/SLTP & 14 & 18,4 \\
ikan & SMA/SLTA & 44 & 57,9 \\
Terakh & Perguruan & 8 & 10,5 \\
ir & Tinggi D3/S1 & 65 & 11,8 \\
Masa & $<5$ Tahun & 9 & 88,2 \\
Kerja & $\geq 5$ Tahun & 67 &
\end{tabular}

Tabel 3.1 diketahui bahwa distribusi frekuensi terbanyak umur responden menurut kelompok umur antara 45 - 49 tahun $(23,7 \%)$ dan kelompok umur terendah berada pada umur 55 - 59 tahun $(6,6 \%)$ dan masih terdapat $(1,3 \%)$ pekerja yang berumur 60 tahun keatas, jenis kelamin responden dengan distribusi terbanyak yaitu laki-laki $(85,5 \%)$ dan perempuan $(14,5 \%)$, jenjang pendidikan yang
Variabel independen yang digunakan dalam penelitian yaitu sikap dan penghargaan. Variabel dependen yaitu kepatuhan, dengan menggunakan data sekunder pengumpulan kartu STOP dalam 6 bulan terakhir.

ditempuh yaitu SMA/SLTA $(57,9 \%)$, dengan masa kerja $\geq 5$ tahun yaitu $(88,2)$.

Tabel 3.2 Distribusi Frekuensi Pekerja dalam Pengisian Kartu Observasi Bahaya

\begin{tabular}{lcc}
\hline \multicolumn{1}{c}{ Variabel } & $\begin{array}{c}\text { Frekuen } \\
\text { si }(\mathbf{n = 7 6 )}\end{array}$ & $\begin{array}{c}\text { Persent } \\
\text { ase (\%) }\end{array}$ \\
\hline Kepatuhan & & \\
Tidak Patuh & 42 & 55,3 \\
$\begin{array}{l}\text { Patuh } \\
\text { Sikap }\end{array}$ & 34 & 44,7 \\
$\quad$ Negatif & 41 & 53,9 \\
$\quad \begin{array}{l}\text { Positif } \\
\text { Penghargaan }\end{array}$ & 35 & 46,1 \\
$\begin{array}{l}\text { Tidak Ada } \\
\text { Pengaruh }\end{array}$ & 45 & 59,2 \\
$\quad$ Ada Pengaruh & 31 & 40,8 \\
\hline
\end{tabular}

(Sumber : Data Sekunder Pengumpulan Kartu STOP Card Dpt.HSE, 2019 dan Data Primer diolah 2019)

Tabel 3.2 diketahui bahwa distribusi frekuensi kepatuhan pekerja sebanyak $(55,3 \%)$ yang tidak patuh dan $(44,7 \%)$ patuh dalam melakukan pengisian kartu observasi bahaya, distribusi frekuensi sikap pekerja yang memiliki sikap negatif sebanyak $(53,9 \%)$ dan sikap positif $(46,1 \%)$, responden yang menyatakan adanya penghargaan yaitu sebanyak $(59,2 \%)$ responden dan yang menyatakan penghargaan yang diberikan tidak berpengaruh yaitu 31 orang $(40,5 \%)$. adanya 
pengaruh yaitu 31 orang $(40,8 \%)$

responden.

\section{Analisis Hubungan antar Variabel Penelitian}

\section{Sikap dengan Kepatuhan dalam Pengisian Kartu Observasi Bahaya}

Hasil statistik hubungan sikap pekerja dengan kepatuhan dalam pengisian kartu observasi bahaya dapat dilihat pada tabel 3.3 sebagai berikut:

Tabel 3.3 Hubungan Sikap dengan Kepatuhan Pengisian Kartu Observasi Bahaya

\begin{tabular}{|c|c|c|c|c|c|c|c|}
\hline \multirow{3}{*}{ Sikap } & \multicolumn{4}{|c|}{$\begin{array}{c}\text { Kepatuhan Pengisian Kartu } \\
\text { Observasi Bahaya }\end{array}$} & \multirow{2}{*}{\multicolumn{2}{|c|}{ Total }} & \multirow{3}{*}{ Sig } \\
\hline & \multicolumn{2}{|c|}{ Tidak Patuh } & \multicolumn{2}{|c|}{ Patuh } & & & \\
\hline & $n$ & $\%$ & $\mathbf{n}$ & $\%$ & $\mathbf{n}$ & $\%$ & \\
\hline Negatif & 28 & 68,3 & 13 & 31,7 & 41 & 100 & \\
\hline Positif & 14 & 40,0 & 21 & 60,0 & 35 & 100 & 0,013 \\
\hline Total & 42 & 55,3 & 34 & 44,7 & 76 & 100 & \\
\hline
\end{tabular}

Tabel $\quad 3.3$ menunjukkan sebanyak 28 orang $(68,3 \%)$ responden memiliki sikap negatif dengan tidak patuh dalam pengisian kartu observasi bahaya. Responden yang memiliki sikap positif dan tidak patuh dalam pengisian kartu observasi bahaya yaitu sebanyak 14 orang (40\%).

Hasil analisis menggunakan uji Rank Spearman di peroleh nilai Pvalue sebesar $(0,013)$, hal tersebut menunjukkan bahwa ada hubungan antara sikap dengan kepatuhan

Tabel 3.5 Hubungan Penghargaan dengan Kepatuhan Pengisian Kartu Observasi Bahaya

\begin{tabular}{|c|c|c|c|c|c|c|c|}
\hline \multirow{3}{*}{$\begin{array}{l}\text { Pengharg } \\
\text { aan }\end{array}$} & \multicolumn{4}{|c|}{$\begin{array}{l}\text { Kepatuhan Pengisian } \\
\text { Kartu Observasi } \\
\text { Tidak }\end{array}$} & \multicolumn{2}{|c|}{ Total } & \multirow[t]{3}{*}{ Sig } \\
\hline & \multicolumn{2}{|c|}{ Patuh } & \multicolumn{2}{|c|}{ Patuh } & & & \\
\hline & $\mathrm{n}$ & $\%$ & $\mathbf{n}$ & $\%$ & $\mathrm{n}$ & $\%$ & \\
\hline $\begin{array}{l}\text { Tidak Ada } \\
\text { Pengaruh }\end{array}$ & 30 & 66,7 & 15 & 33,3 & 45 & 100 & 0,01 \\
\hline $\begin{array}{l}\text { Ada } \\
\text { Pengaruh }\end{array}$ & 12 & 38,7 & 19 & 61,3 & 31 & 100 & 6 \\
\hline Total & 42 & 55,3 & 34 & 44,7 & 76 & 100 & \\
\hline
\end{tabular}

pekerja dalam mengisi kartu observasi bahaya (Hazard Observation Card).

\section{Hubungan Penghargaan dengan Kepatuhan Pengisian Kartu Observasi Bahaya \\ Hasil statistik hubungan penghargaan dengan kepatuhan pekerja dalam pengisian kartu observasi bahaya dapat dilihat pada tabel berikut:}

Tabel 3.5 menunjukkan sebanyak 30 responden $(66,7 \%)$ menyatakan tidak ada pengaruh pemberian penghargaan dengan perilaku tidak patuh dalam pengisian kartu observasi dan responden yang menyatakan adanya pengaruh pemberian penghargaan, namun pekerja tidak patuh dalam pengisian kartu observasi bahaya yaitu sebanyak 12 orang (38,7\%). Hasil analisis dengan menggunakan uji Rank Spearman di peroleh nilai Pvalue sebesar $(0,016)$. 


\section{Pembahasan}

\section{Karakteristik Responden}

Karakteristik responden dalam penelitian ini meliputi umur, jenis kelamin, tingkat pendidikan, dan masa kerja. Berdasarkan hasil penelitian, data yang telah terkumpul diketahui bahwa distribusi responden berdasarkan umur responden terbanyak berada pada kelompok rata-rata umur 45 49 sebanyak $(23,7 \%)$. Dilihat dari umur termuda responden adalah umur 25 tahun dan umur tertua responden adalah 67 tahun.

Bertambahnya usia membuat kemampuan fisik mengalami penurunan, misalnya seperti kekuatan fisik, kemampuan berkonsentrasi dan daya ingat. Hal ini dapat mempengaruhi pekerja untuk berpartisipasi dalam melakukan pengisian kartu observasi dan melaporkan temuan dilapangan mengenai perilaku dan kondisi tidak aman terutama pada saat melakukan observasi dilapangan dan menuliskan temuan tersebut dalam kartu observasi bahaya (Hazard Observation Card). Semakin tua responden, semakin rendah frekuensi untuk melaporkan masalah keselamatan (Adjekum et al., 2015). Bertambahnya usia akan semakin rasional dan makin mampu mengendalikan emosi dan makin toleran terhadap pandangan dan perilaku yang membahayakan (Shiddiq, Wahyu and Muis, 2014).

Berdasarkan hasil penelitian, diketahui bahwa jumlah responden menurut jenis kelamin di PT. $X$, sebagian besar responden yang berjenis kelamin laki-laki sebanyak $(85,5 \%)$ sedangkan jumlah responden yang berjenis kelamin perempuan yaitu sebanyak
$(14,5 \%)$ responden. Setiap tempat kerja memiliki potensi bahaya sehingga pengisian kartu observasi bahaya berlaku bagi seluruh karyawan baik di bagian office maupun dibagian luar office seperti area workshop, jetty, warehouse dan area kerja lainnya.

Penelitian menunjukan bahwa distribusi responden berdasarkan tingkat pendidikan responden dengan frekuensi terbanyak pada jenjang pendidikan SMA/Sederajat yaitu $(57,9 \%)$, sedangkan frekuensi yang terendah adalah jenjang pendidikan Diploma (10,5\%). Pendidikan seseorang berpengaruh dalam pola pikir seseorang dalam menghadapi pekerjaan yang dipercayakan kepadanya, selain itu pendidikan juga akan mempengaruhi tingkat penyerapan terhadap pelatihan yang diberikan dalam rangka melaksanakan pekerjaan dan keselamatan kerja (Notoadmojo, 2012).

Penelitian yang telah dilakukan, diketahui bahwa responden yang memiliki masa kerja dengan distribusi tertinggi adalah pada rentang masa kerja kerja $\geq 5$ tahun sebanyak 67 responden atau (88,2\%), sedangkan distribusi terendah adalah responden dengan rentang masa < 5 tahun sebanyak 9 responden atau (11,8\%). Menurut Sucipto (2014), lamanya seseorang dalam bekerja akan mempengaruhi pengalamannya dalam bekerja. Semakin lama seseorang bekerja maka semakin banyak pengalaman dalam bekerja.

$\begin{array}{ll}\begin{array}{l}\text { Gambaran } \\ \text { dalam Kepatuhan } \\ \text { Observasi Bahaya }\end{array} & \begin{array}{r}\text { Pekerja } \\ \text { Pengisian }\end{array} \\ & \end{array}$


muncul (Geller, 2001). Pemberian penghargaan dapat memotivasi seorang karyawan untuk bekerja lebih baik dan meningkatkan kinerjanya, hal tersebut juga berlaku dalam kepatuhan karyawan mengisi kartu observasi bahaya, dimana karyawan dapat merasa termotivasi membuat kartu observasi sebaik mungkin untuk mendapatkan penghargaan tersebut.

Motivasi yang telah ada dalam diri tenaga kerja untuk berperilaku aman juga harus didukung perusahaan dengan menciptakan lingkungan yang memfasilitasi terjadinya perilaku aman di tempat kerja(Supartha and Sintaasih, 2017).

Peningkatan motivasi dapat dilakukan dengan menerapkan sisitem reward dan punishment. Pemberian penghargaan dapat memotivasi seorang karyawan untuk bekerja lebih baik dan meningkatkan kinerjanya, hal tersebut juga berlaku dalam kepatuhan karyawan mengisi kartu

\section{DAFTAR PUSTAKA}

Adjekum, D. K. et al. (2015) 'CrossSectional Assessment of Safety Culture Perceptions and Safety Behavior in Collegiate Aviation Programs in the United States', International Journal of Aviation, Aeronautics, and Aerospace, 2(4).

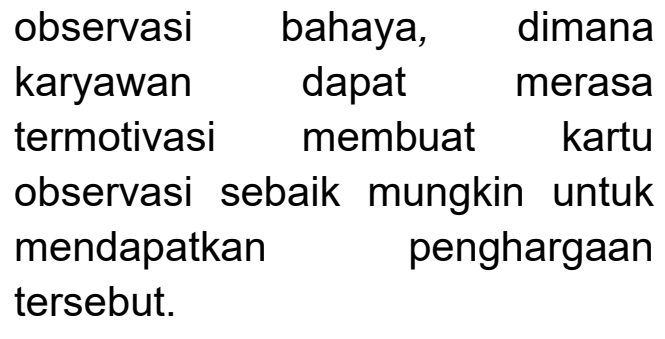

\section{SIMPULAN}

Berdasarkan hasil observasi, analisa data dan pembahasan dari beberapa variabel yang dinilai berkaitan dengan kepatuhan pekerja dalam pengisian kartu observasi bahaya (Hazard Observation Card) di PT. X, maka diperoleh kesimpulan sebagai berikut :

1. Ada hubungan antara variabel sikap dengan kepatuhan pekerja dalam pengisian kartu observasi bahaya (Pvaule = 0,013).

2. Ada hubungan antara variabel penghargaan dengan kepatuhan pekerja dalam pengisian kartu observasi bahaya dengan nilai ( $P$ vaule $=$ 0,016).

BPJS ketenagkerjaan Indonesia. 2019. Data kasus Kecelakaan 2019.

Ekayani, N. P., Wardhani, V., \& Rachmi, A. T. 2017. Nurses' Intention and Behavior in Reporting Adverse Event: Application of Theory of Planned Behavior. Kesmas: 
National Public Health Journal, 11(3), 138-144.

Geller, S. 2001. The Psychology of Safety Hand Book. USA: Lewis Publisher. Hal 25-27.

International Labour Oganization (ILO) Kasus Kecelakaan Kerja 2018.

NSC (National Safety Council). 2013. Injury Facts. Edition. Itasca, IL:

Sucipto, C. D. 2014. Kesehatan Keselamatan Kerja. Yogyakarta: Gosyen.

Soekidjo, N. 2012. Promosi kesehatan dan Perilaku Kesehatan. Jakarta: Rineka Cipta.

Shiddiq, S., Wahyu, A. and Muis, M. 2014. Hubungan Persepsi K3 Karyawan dengan Perilaku Tidak Aman di bagian Produksi Unit IV PT. Semen Tonasa. Jurnal. Makasar: K3 Fakultas Kesehatan Masyarakat Universitas Hasanuddin.

Sunyoto, D. 2013. Teori, Kuesioner, dan Proses Analisis Data "Perilaku

Organisasional'. Jakarta:CAPS (center for Academic Publishing Service).

Supartha, W. gede, \& Sintaasih, D. K. 2017. Pengantar perilaku Organisasi; (Teori, kasus dan Aplikasi penelitian). Program
Studi Manajemen Fakultas Ekonomi dan Bisnis Universitas Udayana. Denpasar Timur: CV. Setia Bakti.

Suryatno, 2015. Evaluasi Implementasi Kartu Observasi Bahaya. Skripsi Fakultas Kesehatan Masyarakat Universitas Muhammadiyah Semarang. 10(2)

Wahyuni, Fitri. 2017. Hubungan Pelatihan, Pengawasan, Penghargaan dan Sanksi terhadap Kepatuhan Karyawan dalam mengisi Hazard Observation Card di Departemen Production Coordination and Transmission VICO Indonesia. Skripsi, Fakultas Kesehatan Masyarakat Universitas Mulawarman.

Winnaputri, Nuralmasdini, Hanifa Maher Denny, \& Ekawati. 2017. Studi Presepsi dan Niat Pekerja alam melaporkan kejadian berbahaya dan Kecelakaan di Terminal Petikemas Semarang. Jurnal Kesehatan Masyarakat, 5(5),

WSH Concil. 2014. WHS Guide to Behavioural Observation and Intervention. 